\title{
Strategic Approach to Successful Implementation of Innovation Changes in SMEs
}

\author{
Andrea Gazova ${ }^{1}, Z_{\text {Zuana Papulova }}{ }^{1}$, Emilia Papulova $^{2}$ \\ ${ }^{1}$ Department of Strategy and Entrepreneurship, Faculty of Management Comenius University \\ in Bratislava, Slovakia \\ ${ }^{2}$ University of Economics in Bratislava, Slovakia \\ andrea.gazova@fm.uniba.sk
}

\begin{abstract}
The submitted paper deals with issues of innovation, strategic approach to innovation and its role to support competitiveness in small and medium-sized enterprises. The purpose is to highlight the importance of strategic approach to implementation of innovation changes and application of factors contributing to successful innovation implementation. To successfully implement innovation is a major challenge for SMEs, who see it as an important opportunity to build sustainable competitive advantages and promote business success. We specialized on approach of SMEs, as compared to large companies they encounter several obstacles. Based on our research, we present findings on approach to innovation from 164 managers of SMEs in Slovakia.
\end{abstract}

Keywords: SMEs, Innovation, Strategic Approach

\section{Introduction}

Small and medium-sized enterprises (SMEs) plays an important part for national economies. Their important contribution to the national economy is crucial as they create a substantial part of employment as well as added value. SMEs are often the bearers of positive structural changes in the economy, increasing its productivity and contributing to economic growth. From the point of innovations, SMEs contribute to commercializing new technologies and innovative ideas. [1] Especially in last years, contribution of SMEs to innovation is widely recognized. They are playing an ever-increasing role in innovation, driven by changes in technologies and bringing new ideas to the market. [2]

An effort of enterprises for creating and developing innovation and application of innovation changes presents one of the key factors leading to their performance and competitiveness. Innovativeness can help to reduce costs, to implement new machines and technologies or to prepare and produce products and services improved to better match changes on the market. [3] The ability to develop new products is important because the environment is constantly changing. Competitors may launch new products that pose a serious threat to the company's existing market position. The company must have the capacity corresponding to the product innovation. New products are often considered to be the main manifestation of innovation in the market, but process innovation 
also has an equally important strategic role. A significant source of advantage can often be the ability to do something that no one else knows, or to do it in a better way than the competition. Innovation is today called to be the main tool for the competitiveness of companies. [4]

This paper deals with issues of innovation, strategic approach to innovation and its role to support competitiveness in SMEs. The purpose is to highlight the importance of strategic approach to innovation and to evaluate approach and successfulness of innovation on selected sample of SMEs in Slovakia.

\section{$2 \quad$ Literature review}

\subsection{Innovations and process of innovation}

The ability of companies to innovate is one of the key factors in positive structural change. Purposeful use of new (progressive) knowledge in all business activities is positively reflected in the growth of labor productivity, growth of added value of production and increasing competitiveness (based on the quality of production), not only at the company but also at the national level. [1]

Innovation affect everyday life. In its complexity, innovation is a dynamic, systematic and developmental process that involves the creation of new ideas and their practical implementation. The result of this process is a positive change that is oriented towards filling the needs of society and improving the whole reproductive process. [5] Although in practice, we see the perception of innovation as a realization of a casual idea, in most cases innovation is the result of a purposefully managed process. Innovation can be seen as an introduction of a new type of a product, as existing product with new characteristics, as an application of a new production process, as an opening a new market, as an obtaining new sources of raw material, or as a development of new system of production. [3]

The process of innovation begins with identifying opportunities. Subsequently, the company proceeds to evaluate the potential of opportunities and to decide on its possible use. After identifying opportunities and analyzing the effects and risks, innovators must not forget to manage the innovation process. The next steps are the generation of ideas and their elaboration. After selecting and elaborating the topic, the resources necessary for its implementation are allocated. This is where real concept development begins, and the innovation process blends with the product development process. [5] Many innovators are already trying to get feedback from customers at this step, and then carry out a follow-up review. The better a business understands the innovation process, the more effective it becomes in implementing innovations that promote sustainable growth. $[3,4]$ Innovations are thus closely linked to management.

\subsection{Innovation in SMEs and strategic approach}

As authors pointed out, a successful innovation is crucial for business success. [4] According to OECD studies, SMEs innovate, but not as much as large firms on average and tend to be less involved in collaboration for innovation activities on average. [2] 
The approach of innovation by SMEs compared to large companies encounters several obstacles. SMEs can strive with various disadvantages: $[1,2,6]$

1. Resources (e.g. limited financial resources; lack of equity; high costs of production differentiation; lack of staff and experts, non-existing department specialized on R\&D or innovation).

2. Information (e.g. educational barriers, consisting of a lack of both professional and managerial knowledge, knowledge and experience; information barriers because of a malfunctioning information system).

3. Productivity (e.g. insufficient motivation; lower labor productivity; excessive workload of owners).

4. Environment (e.g. difficulties in obtaining quantity discounts from suppliers; smaller local markets; strong competition; instability of the macroeconomic environment).

To overcome these obstacles, SMEs should think strategically how to design and implement their innovation management. To reduce disadvantages coming from their size, it is recommended for SMEs and especially for small companies not to innovate by only themselves but to search for the collaboration, e.g. with suppliers, customers, competitors, universities, research organization or others. [2] Collaborations and creating networks should be part of company strategy in SMEs. By participating in cooperation networks, SMEs can reduce their own deficit of the knowledge base, resources for innovation and the risks associated with innovation. [1]

The fundamentals of strategic approach are linked to gaining the knowledge of trends and the ability to predict the future. Those who exploit and apply the future development as soon as possible and as accurately as possible is and will be successful. Particularly those companies will be successful that will be able to anticipate breakthroughs (e.g. revolutionary discovery, technological progress, the onset of the crisis) [7] and adapt innovative solutions and innovative changes in companies, whether in terms of product, process changes, penetration to new market or strategic partnership.

Also, a well-chosen strategy plays very important role for SMEs in pursuing innovation. For business success, it is very important to prepare adequate strategy that presents preparation for the future. From this view, strategy should be based on forecasting the future development, possible opportunities and risks from external environment and is focused on providing effective internal changes. [8] From the view of external environment, challenges can arise from trends in macro, interactive and microenvironment. Macro environment consists of lot of factors that affect political, legal, economic, social, technical trends. This is the part of environment that is currently bringing a lot of challenges and new trends as well as threats. [9] Opportunities in external environment can be also affected by interactive environment composed by subjects that can affect companies even that are not part of the same industry. Subjects of interactive environment can influence a lot of other subjects regardless of specific industry. Interactive environment involves financial institutions, shareholders, universities, communities, unions, media and associations. [8] All subjects of interactive environment are viewed as potential partners, also in terms of partnership in innovations. Business chances of SMEs to innovate are directly affected by industry and situation on the markets in which 
businesses operate. [3] Examination of industry environment is focused on understanding of forces influencing industry. Companies should have a knowledge about their competitors, their products, customers need and all other subjects influencing the market. [9] All these examinations and analysis of external environment contribute to innovation and formation of innovative business strategy. $[8,10]$ Especially new and small companies have an ability to recognize and exploit the commercial opportunities emerging from technological, competitive and market changes. [2]

For successful innovation management in SMEs, it is also very important to create the environment and processes that stimulate employees' enthusiasm and motivation for innovation. [11] Innovative companies often do not have a hierarchical structure. They have flexible structure and open access to innovation and innovation activities, where everyone can contribute to creating something new through innovative approaches. In such innovative businesses, it is needed from every employee to think about the future in business, and so participate in creating new ideas. [11] The main driver of innovation change is the human factor and its creativity and initiative approach. [12] In order to make successful change, managers need to support people, and develop an innovative culture in an enterprise. $[13,14]$ In the company innovation process should have a permanent nature with purpose of continual improvement. All employees should be involved into the innovation process, which should also be facilitated by free access to information, feedback and collective spirit. [10]

\section{Methodology}

We assume that the number of successfully implemented innovations depends not only on monitoring competition, but also on monitoring and responding to trends from the external environment and on collaboration with other subjects on the market. Based on research projects from 2016 - 2020, we examined the approach of SMEs to innovation and innovation management.

The framework for examination is based on evaluation of theoretical knowledge in the field of innovation, implementation of innovation changes and strategic approach to generation of sustainability of competitiveness in SMEs. Theoretical framework of knowledge creates the basis for providing empirical research with evaluation of findings and formation of conclusions. Then, we used the questionnaire to collect the data. Our sample consisted of 164 managers from SMEs operating in Slovakia. The services sector was the most represented, accounting for up to $46.95 \%$ of companies. From the point of view of the national economy, this sector is also referred to as the tertiary sector and includes all sectors of human activity whose essence is the provision of services. The manufacturing sector was represented with $12.20 \%$ and the information technology sector with $8.54 \%$ of respondents. The management of the process of innovation change is the subject of all industries, therefore the results of the whole set of companies were processed.

In data processing, we used statistical methods allowing quantification, numerical expression of findings as frequency or percentage expression and we also used regression analysis to create regression model on main findings. 


\section{$4 \quad$ Results and discussion}

In the following chapter, we present the results and findings of analyses and examination about current state in innovation management and innovation changes in SMEs.

\subsection{Main reasons for innovation activities in SMEs}

The SMEs environment is currently a very rapidly changing environment, which is largely exposed to the challenges of the development of new modern digital technologies, which are becoming widespread in almost all sectors. Due to the dynamic development in the world, it is necessary for our SMEs to respond to the changes that are taking place in their environments and to maintain the competitiveness of other SMEs in other countries.

When examining the main reasons to implement various innovations in SMEs, managers were instructed to respond in the scale 1 to 7 giving importance to the factors (with 1 meaning less importance, 7 meaning highest importance).

The most common reasons (Fig. 1) why companies have been innovating lately are:

- process optimization - was mentioned as the main reason for innovation change by $24.4 \%$ of SMEs. The companies decide thoroughly to analyze current processes (not only of a production nature) and focus on their streamlining and innovation. They are aware that modern technologies greatly help businesses to streamline certain processes, increase productivity and thus their competitiveness.

- cost optimization - innovation due to costs and their optimization was identified as the main reason by $31.1 \%$ of SMEs. The digital transformation will undoubtedly significantly affect the way several sectors operate, it will affect the efficiency of their production, and operational processes, whether in terms of time or costs.

- operational risk mitigation - operational risk mitigation was identified as the main reason by $11.6 \%$ of SMEs. Less importance was assigned to risk mitigation in operational processes (median 4). SMEs can use operational risk strategy to identify and analyze risks in their operations and take corrective actions to mitigate these risks.

- increase in revenues - was identified by up to $31.1 \%$ of SMEs. The highest importance as the reason to innovate was given to the factor of revenues growth which seems to be motivating SMEs to implement innovative changes.

- market penetration - was reported by $12.2 \%$ of SMEs. Some enterprises, especially small firms, choose to pursue increasingly specialized markets or innovative niches, which exist both in the home country and in foreign markets.

- increase in market share - was reported by $15.9 \%$ of reported SMEs. The widely spread of ICT, combined with a rapid fall in prices and an increase in the performance of these technologies, has contributed to the development of new activities in the private and public sectors. Together, these technologies have increased market size and reduced costs, enabling the development of new products and services. ICT technologies have also contributed to the way products and services are produced and distributed to final consumers, including business models used by companies ranging from small start-ups to large multinationals. 
Fig. 1. The main reasons for innovation activity

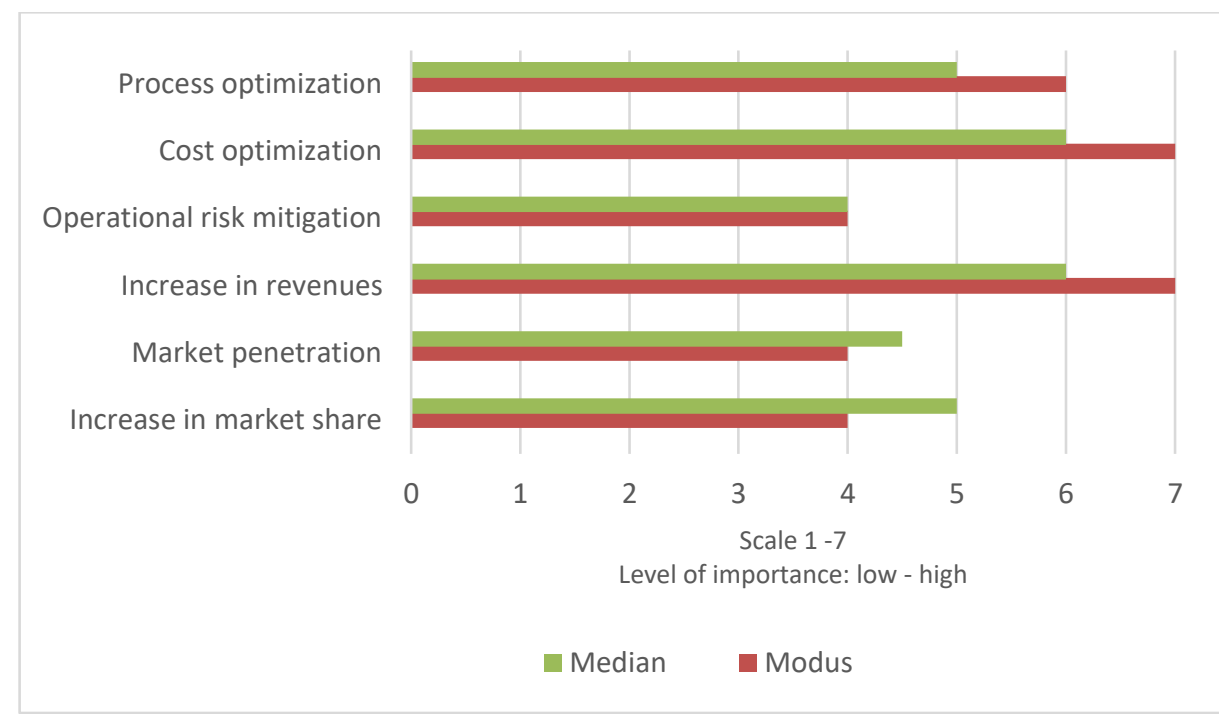

\subsection{Monitoring of competition, industry, and trends from the external environment}

Historical and up-to-date information on any part of the production process or on the product itself can be recorded and can be accessed at any time, which allows constant monitoring and evaluation of the information with a view to timely prevention of error production. Monitoring this information from external environment is essential for formulating suitable strategy and for timely change readiness.

Due to the importance of different types of information sources in the management of innovation change, companies (almost 48.2\%) considered market sources such as suppliers, customers, competitors, and consulting companies to be the most important source of information. The $37.2 \%$ of companies stated this type of information sources as significant. Internal sources of information for effective management of innovation activities were considered very important by $34.1 \%$ and $41.5 \%$ stated this type of information sources as important.

Other sources of information, such as associations, conferences, and professional publications, are considered by $18.9 \%$ of companies to be an unimportant source of innovation and $35.4 \%$ of companies consider these sources to be of little importance. With institutional sources of innovation activities such as universities, colleges, and state institutions, $22 \%$ of companies consider an unimportant source for their activities 
related to innovation change and $36.6 \%$ of companies as less important. The most frequent answers therefore assigned a value of 1 to this reason and the average value corresponded to 3 .

Only $29.8 \%$ (48 of SMEs) stated that they monitor innovations and changes in competition and $70.2 \%$ (113) of companies do not have a structured process for monitoring innovations and changes in competition.

Despite the informal process of monitoring changes in competition, they try to monitor competition, especially via the Internet. $25.6 \%$ of companies from the surveyed sample regularly monitor trends in innovation changes outside their industry, $45.7 \%$ of companies stated that they monitor these trends only occasionally and up to $28.7 \%$ of companies do not follow trends in innovation changes outside their industry at all.

Strategic decisions of competitors had no impact on the company and its innovative changes in $17.7 \%$. Some influence was confirmed by $53 \%$ of companies and in $28.7 \%$ of cases the competition had a significant effect on the company.

In order to successfully accelerate the innovation potential, it will be necessary to build an institutional background supporting technological and innovation at regional levels or to start more intensive interconnection of locally operating SMEs in regions with insufficiently developed infrastructure to support innovation of new technologies with regional-built infrastructure.

Another obstacle is the low level of involvement of universities and colleges in nontechnical fields in applied research. Insufficient link between education through practice and practice and lifelong learning: deteriorating structure and quality of graduates in the educational process. This was confirmed by our sample when the information source about the innovation activities from such institutions are evaluated as less important.

\subsection{Collaboration}

When implementing innovation changes, $51.2 \%$ of managers of SMEs mentioned cooperation with their suppliers, $46.3 \%$ cooperate with their customers in innovation activities and the third most frequently mentioned partner for innovation changes was another company in the strategic group according to $36.6 \%$ of companies. (Fig.2)

Fig. 2. The forms of collaboration 


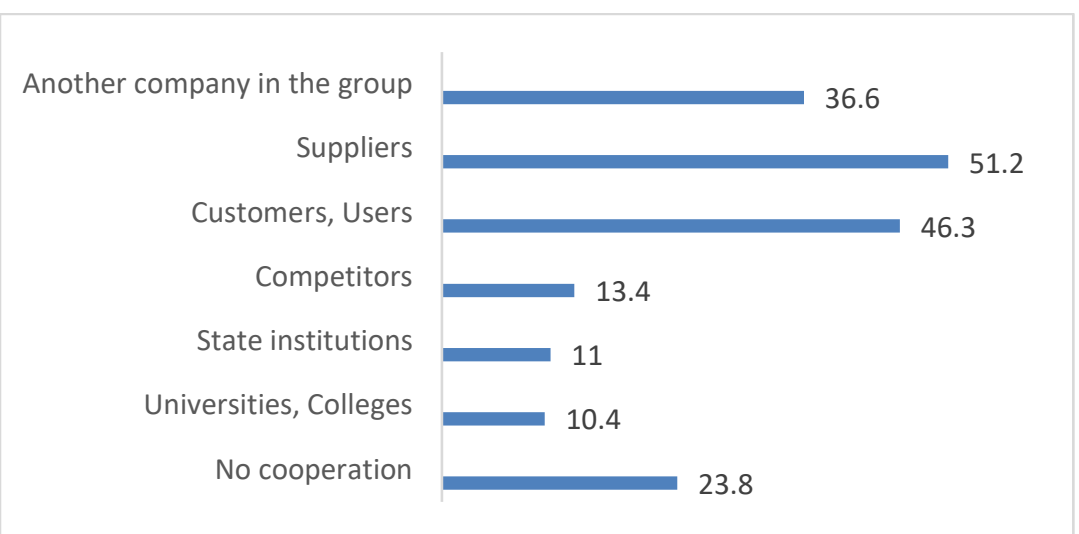

Only $7.9 \%$ of companies used the form of state support for the implementation of innovative changes in the company, $92.1 \%$ of small and medium-sized enterprises do not consider this form to be relevant.

An effective and transparent regulatory environment is key to entrepreneurship and the development of SMEs at all levels of the business life cycle, including business entry, investment, expansion or closure. By reducing the regulatory burden on SMEs, government can facilitate the active participation of businesses not only in the local but also in the global economy. It is SMEs that have bigger problems with the implementation of regulatory restrictions than larger companies. In the last 2-3 years, we have observed a positive trend of reducing the administrative burden, at least for start-ups, associated with fewer barriers to market entry and reducing compliance costs in various areas.

The government will also try to reduce the administrative burden on start-ups by lowering legal barriers to entry and reducing compliance costs. Despite this effort to support young innovative companies, it partially forgets the established business entities, which are still exposed to relatively high administrative complexity.

The main goal is to streamline communication between individual offices and ministries. The aim is to ensure that the institutions are able to exchange information with each other and not burden businesses. On the other hand, there are several obligations arising from various legal regulations and ordinances that administratively complicate the lives of Slovak entrepreneurs.

\subsection{Success of innovation changes}

In order to find out the approach of companies to evaluating the success of innovative changes, we asked if they regularly evaluate this success. $22 \%$ of companies with high regularity trace back the success of innovation changes. More than one third of companies $(34.1 \%)$ carry out an evaluation of the success of innovative changes with a medium degree of regularity, and $6.7 \%$ of companies do not monitor the success of implemented changes at all. From a scale of 1 to 7 , the most frequent companies attached value with the highest weight of importance to the regular evaluation of the success of the implemented changes (7). The median was 5 when answering this question. 
In the last five years, the company has managed to successfully introduce and implement one to three innovative changes in $40 \%$. The second most common response in $32.3 \%$ was four to six successful changes. Almost $10 \%$ of companies managed to successfully implement from seven to nine changes, and in $17.1 \%$ of cases more than ten innovative changes were implemented. This percentage is shown graphically in Fig.3. The number of successfully implemented changes reflects the correctly and effectively management of the process of innovative changes in companies. The median response was four to six successful changes. On average, companies have not been able to implement one change every two years.

Fig. 3. Successfully implemented innovative changes

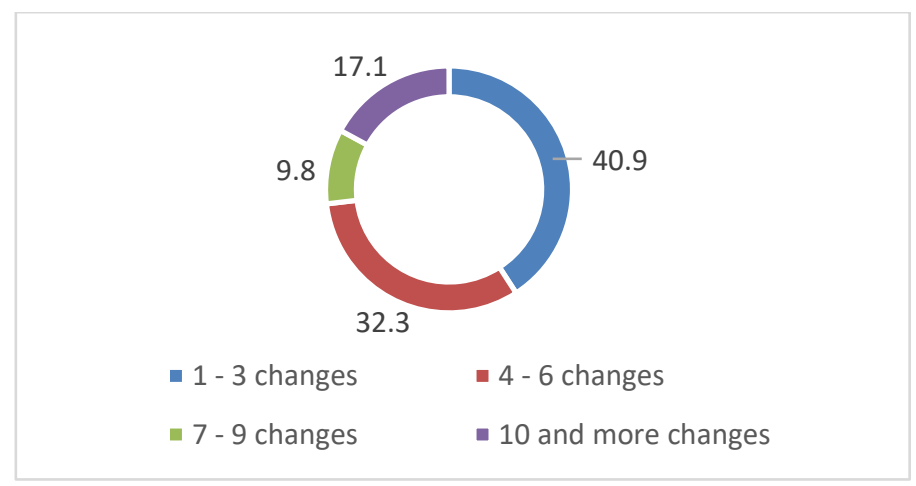

In the past five years, $73.2 \%$ of the surveyed companies have failed to successfully introduce and implement one to three innovative changes (Fig.4). The second most common response $(36 \%$ ) was a failure to report four to six changes. Almost $5 \%$ of companies failed to implement successfully from seven to nine changes and in $6.1 \%$ of cases they failed to implement more than ten innovative changes. The number of unsuccessfully mentioned changes thus reflects the degree of insufficiently effectively managed management of the process of innovative changes. The median response was one to three unsuccessful changes. On average, companies were unable to implement only one change per year.

Based on the failure to implement change, we were interested in the phase in which the implementation of innovation change was most often canceled. Half of the companies stated that the innovation process was canceled in the concept phase and almost half $(43.7 \%)$ of companies identified the critical initial phase of the implementation of innovation change. In $1 / 3$ of the cases, the process of implementing innovative changes in the company was not canceled at any stage of the implementation and thus proceeded smoothly until successful implementation.

Fig. 4. Failed implementation of innovative changes 


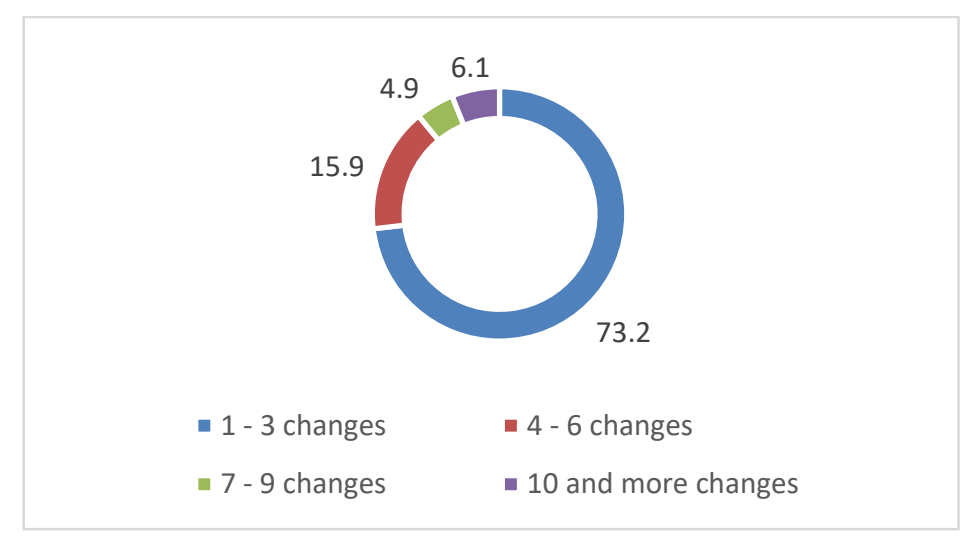

Based on the theory, which defines innovation activity as the creation of something that did not exist or a combination of existing experience, we believe that in developing innovation activities it is necessary to monitor not only competition and industry in which the company operates, but also trends outside its industry.

We assume that the number of successfully implemented innovation changes depends furthermore on monitoring competition, on cooperation with other entities and evaluating the success of already implemented innovation changes.

\subsection{Regression model of successful implementation of innovation changes}

Based on the results of a study of companies' approach to products in relation to innovation change, which shows that only one in six companies has an structured R\&D process in place on average, that $22 \%$ of companies regularly monitor the success of innovation change and more than one third of companies evaluate the success of innovative changes with a medium degree of regularity.

We also found that, companies managed to successfully implement one successful change per year and, conversely, failed to implement one change every two years. When introducing innovative changes into practice, problems arose, especially in the initial stages of implementation, when the innovative activities of the company were canceled.

In connection with these findings, we analyzed a regression model (Table 1), and thus we determined which factors appear to be significant in the survey, which affects the number of successfully implemented innovation changes. We revealed that monitoring trends outside the industry, the cooperation of the company in introducing innovative changes with the competition and the cooperation with another company in the group has a significant impact.

To evaluate this statement, we use the values of $\alpha$ for these factors, which are $\alpha<0.05$ and thus these explanatory constants are statistically significant. For the other explanatory variables of this model, the result is $\alpha>0.05$, and therefore we will not deal with them further. This model explains $27 \%$ of the impact on the number of successfully implemented innovation changes (Adjusted R significance level). 
Table 1. Regression analysis of the success of innovative changes implementation

\begin{tabular}{|c|c|c|}
\hline & Model 1 & Model 2 \\
\hline & $\begin{array}{l}\text { Success of } \\
\text { changes }\end{array}$ & $\begin{array}{l}\text { Success of } \\
\text { changes }\end{array}$ \\
\hline Monitoring competitors & $-.02 *(.06)$ & ------- \\
\hline Monitoring trends outside the industry & $.24 * * *(.07)$ & $.26 * * *(.06)$ \\
\hline Cooperation with competitors & $.21 * * *(.08)$ & $.23 * * *(.08)$ \\
\hline Cooperation with customers & $.05 *(.05)$ & ------- \\
\hline Cooperation with company inside the group & $.14 * *(.06)$ & $.16^{* * *}(.06)$ \\
\hline Evaluation of success of past changes & $.02 *(.01)$ & \\
\hline $\begin{array}{l}\text { Adjusted R significance level } \\
\text { Standard error in parentheses } \\
\text { Significance level } *<0.1, * *<0.05, * * *<0.01\end{array}$ & .27 & .27 \\
\hline
\end{tabular}

Information barriers are obstacles which can influence monitoring of industry trends outside the enterprise. Under these we can understand problems in identifying, selecting and contacting international markets due to information inefficiency, as well as obtaining, evaluating and understanding the local market in which businesses operate. Another obstacle can be limited information needed to analyze the market or insufficient ability to understand and analyze available data. Despite the large amount of information available of various kinds, it may be difficult for SMEs to obtain relevant information that would allow them to better map the domestic foreign market.

In the future, cooperation and communication between organizations will be essential. Networking and interconnection are central elements of Industry 4.0. Workers will collaborate and communicate in real time without borders using intelligent devices. The Internet provides the opportunity to meet in virtual rooms almost anytime and to obtain the required information as needed for innovation change. All kinds of information and data will be ubiquitous and at the fingertips of employees, leading to a whole new level of knowledge management.

\section{Conclusion}

In today's highly dynamic and competitive business environment, businesses are exposed to challenges and increasingly encountering ever-increasing market demands and customer expectations. In order to ensure the success of a company, managers need to implement innovations and support the innovative behavior of their employees. Innovation and innovation management, as well as change as such, are now becoming more 
and more of a declension. This is a highly discussed topic and its importance grows with societal changes such as the upcoming Industry 4.0.

Innovation management needs to be integrated into the whole management system of the company and supported by management functions. Managing innovation change in SMEs also needs to be aligned with particularities of these businesses and the conditions in which they operate. Necessity of strategic thinking in order to prepare SMEs for the future, and through innovation and change management, to build competitive advantages for businesses.

Strategic approach is highly important element supporting organizational success. The need to know what the business is about, what it is trying to achieve and which way it is headed is influencing the effectiveness in the firm. The ability of an enterprise to manage innovation change is closely linked to its ability to plan, design and effectively implement various types of innovation change.

Furthermore, we found out that companies managed to successfully implement one successful change per year and, conversely, failed to implement one change every two years. Almost $74 \%$ of companies experienced the failure of 1-3 changes per year. The failure in implementing such a change was mostly detected in the initial stages of implementation.

From the strategic perspective it is also alarming that the companies do not monitor the information from the environment regularly and overall monitoring of business industry and subjects operating on the market was of less importance.

According to the presented regression model, in determining that the number of successfully implemented innovative changes is most influenced by monitoring trends outside the industry in which the company operates. The statistically significant impact on the number of successfully implemented innovative changes in cooperation was also confirmed. The positive impact of cooperation with competitors and cooperation with another company in the group was proven. Based on the fact that monopolies push small and medium-sized enterprises out of the market, the results of the regression model thus explain the impact and importance of cooperation between small and medium-sized enterprises, especially with competitors and other companies in the group.

Another serious problem could be lack of business strategy (especially in the context of micro-small enterprises), resp. the absence of a medium- and long-term strategy that would define the objectives and the way to achieve them. In connection with the implementation of the intelligent industry, we are talking about the application of modern technologies for the analysis of ex-post data of the company and the environment in which it operates. These data would serve as a basis for the preparation of the concept of the company's strategy for the future.

\section{Acknowledgements}

This research was supported and funded by APVV-17-0656 titled Transformation of Paradigm in Management of Organizations in the Context of Industry 4.0. 


\section{References}

1. Jeck, T.: Malé a stredné podniky na Slovensku a v Európskej únii: Bariéry, financovanie a inovačné správanie. Ekonomický ústav SAV, Bratislava (2014).

2. OECD: SMEs, Entrepreneurship and Innovation. OECD publishing, (2010).

3. Drucker, P. F.: Innovation and Entrepreneurship. Reprint edition, Harper Business, USA (2006).

4. Cruz-Cunha, M. M., Varajao, J.: E-Business Issues Challenges and opportunities for SMEs: Driving competitivness. IGI Global, Hershey (2010).

5. Čimo, J.: Inovačný manažment. $1^{\text {st }}$ edn. Ekonóm, Bratislava (2010).

6. Chodosová, A., Bujnová, D.: Podnikanie malých a stredných podnikov. $2^{\text {nd }}$ edn. Ekonóm, Bratislava (2008)

7. Štedroň et al.: Prognostika. 1st ed. C.H.Beck, Praha (2019).

8. Papula, J., Papulová, Z., Papula, J.: Strategický manažment. Aktuálny concept pre rýchlo sa približujúcu budúcnost'. Wolters Kluwer, Praha (2019).

9. Gajdošíková, K.: Manažment procesu inovačných zmien v malých a stredných podnikoch. EU FPM, Bratislava (2016).

10. Papula, J., Volna, J.: A Descriptive Analysis of Intellectual Capital Concept Implementation within Slovak Companies, Driving the Economy through Innovation and Entrepreneurship: Emerging Agenda for Technology Management. Springer India, 485-93 (2012).

11. Stacho, Z., Stachova, K., Caganova, D.: Participation of all Employee Categories in Innovation Processes in Slovak Organisations. Mobile Networks and Applications, 1-7 (2020).

12. Stachova, K., Stacho, Z., Blstakova, J., Hlatka, M., Kapustina, L. M.: Motivation of Employees for Creativity as a Form of Support to Manage Innovation Processes in Transportation-Logistics Companies. Naše More 65(4), 180-186 (2018).

13. Lizbetinova, L., Lorincova, S., Caha, Z.: The Application of the Organizational Culture Assessment Instrument (OCAI) to Logistics Enterprises. Naše More 63(3), 170-176 (2016).

14. Blštáková, J., Bednár, R., Adamková, H., Joniaková, Z., Ljudvigová, I., Némethová, I., Skorková, Z.: Human Resources Management 4.0: Architecture, Roles, Leadership, and Business Models. 1st Edition. Verlag Dr. Kovač, Hamburg (2019). 